\title{
Os sonhos intranqüilos de Franz Kafka: um horizonte interpretativo de A Metamorfose
}

\author{
Marcelo José de Sonsa ${ }^{1}$
}

É muito provável que, 76 anos depois da morte de Kafka, a familiaridade com o atributo kafkiano - um símbolo por certo abusivo de homogeneidade - como sinônimo de incompreensível, pode isentar-nos de possuir um projeto otimista de interpretação de seus escritos, objeto de tantas discrepâncias. O que chamamos "obra" de Kafka persiste um corpo de romances, narrativas, cartas, diários, e fragmentos, os quais, não fosse a desobediência de seu amigo Max Brod a seu último pedido - Kafka lhe ordenara que os destruísse - não seriam nunca publicados. Ironicamente, Brod tornou-se o responsável pela sobrevivência destes escritos, publicando-os todos após a morte de Kafka. Não há, nesse sentido, nada mais estranho à idéia clássica de obra - e parece não haver em toda a literatura deste século, nenhum outro exemplo de tão radical oposição à idéia da obra como monumento perene que o escritor, pela via da publicação, lega à posteridade.

"Principal aspiração, sua única vocação, a literatura era, para Kafka, a própria vida ou, melhor, a possibilidade de resolver a vida em escrita" explica Abel Barros Baptista, em artigo intitulado "O corpo incompleto".2 Como escreveu Walter Benjamin, num ensaio publicado no décimo aniversário da morte de Kafka, sua obra não são parábolas e, ao mesmo tempo, não se pode lê-la em sentido literal; narra acontecimentos únicos, mas parece que o faz com o exclusivo propósito de exprimir uma doutrina ou uma verdade geral, a que, no entanto, não acedemos nunca, sem que sequer possamos supô-las inacessíveis. " ${ }^{3}$ Em Kafka, a demanda da literatura não se enraíza senão no circuito de si mesmo" afirma Luiz Costa Lima.

Ao longo das décadas posteriores à morte de Kafka [1883-1924], seus escritos intrigaram os intérpretes, bem como haviam constituído um estorvo para os primeiros críticos que tentaram interpretá-la através da práxis interpretativa da modernidade. Costa Lima constata que alguns dos primeiros resenhadores e intérpretes tinham sensibilidade suficiente para compreender que o relato kafkiano trazia um problema imediato da interpretação. A fim de explicar esse problema, Costa Lima pergunta-se: sob

1 Graduação - História/UFPR. O autor é bolsista do PET-História.

2 Folha de São Paulo, caderno Mais!, 30 de maio de 1999. Pág. 5. Abel Barros Baptista é professor da Universidade de Lisboa e diretor-adjunto da revista portuguesa "Colóquio-Letras".

3 BENJAMIN, Walter. Franz Kafka. A propósito do décimo aniversário de sua morte. IN: Obras escolhidas. Vol. 1. São Paulo; Ed. Brasiliense, 1986.

26

Qevista \$ernáculo 
qual ótica hermenêutica estes olhares estavam sendo guiados? Para ele, a hermenêutica moderna dera relevância primordial à voz autoral e tomara por missão a sua explicitação plena, se possível, além da própria intenção autoral. "Para se realizar, esse projeto pressupunha o objeto textual investido de duas ordens de coerência: a coerência dos valores poeticamente manifestados com uma certa ordem da sociedade. Daí resultava que uma obra poética podia ser criticamente valorizada desde que, por sua própria crítica, sinalizasse o projeto de uma sociedade reformada".

Mas apesar da sofisticação exegética alcançada, privilegiou-se ora a dimensão existencial, ora a dimensão psicanalítica freudiana. Para sair destas interpretações reducionistas, Costa Lima ressalta o desacordo entre o objeto kafkiano e o paradigma da modernidade, orientando sua análise para o teor corrosivo de uma ficção que possibilita o questionamento sensível das verdades assumidas. ${ }^{4}$

Assim, Costa Lima analisa parte do material crítico produzido a respeito de Kafka, realizando uma reflexão que nos permite pensar no questionamento do estatuto moderno de ficção. Aproveitando-se da proximidade que os textos privados de Kafka têm com sua produção ficcional, Costa Lima realiza, em um primeiro momento, um percurso através destes textos privados - diários e cartas - para ensaiar os instrumentos que posteriormente serão postos em uso pelo estudo de "O julgamento", "Na Colônia Penal" e "O Processo". São nestes instrumentos que acreditamos buscar, neste estudo, uma estabilidade na interpretação que realizaremos de "A metamorfose".

Luiz Costa Lima procura superar o impasse com as demais interpretações de Kafka, centralizando sua análise na questão da Lei, da Autoridade. A compreensão de passagens obscuras na obra de Kafka é feita através do método das passagens paralelas, buscando numa ou noutra obra uma referência que solucione a passagem problemática. Neste sentido, Costa Lima busca primeiro compreender a relação que aquele autor estabelece com sua literatura, destacando que, para Kafka, "o ato de escrever é uma urgência de resgate e liberação". ${ }^{5}$

Kafka vê a literatura como um absoluto. Como dizia em carta de 30 de novembro de 1912 a Felice, sua noiva: "Escrever mal, dever contudo escrever, se não se quiser abandonar-se ao desespero completo". E sua ansiosa fixação volta a ser referida em carta datada de 11 de dezembro, do

4 LIMA, Luiz Costa. Limites da voz: Kafka. Rio de Janeiro; Rocco, 1993.

5 LIMA, Luiz Costa. Op. Cit. Pág. 26. 
mesmo ano:

"(...) Agora a noite tive oportunidade de escrever, o que toda minha natureza pedia, se não diretamente, com um desespero interno crescente, mas só escrevo o estritamente necessário bastante para suportar o outro dia (...)"6

A relação amorosa entre Kafka e Felice poderia ser comparada a um sistema de tráfego com duas mãos. Na direção Kafka-Felice, circulam dejetos (a escrita), o processo físico de descarga; na direção oposta, Kafka recebe de Felice alimentos, o processo químico do fortalecimento. A questão do matrimônio é pertinente dentro deste processo, pois Kafka acreditava que seu trabalho literário estava em perigo com o matrimônio.

A escrita tornava-se uma obsessão que reunia todas as suas forças; consequentemente, seu trabalho, o escritório, e inclusive o matrimônio eram ᄀlhe um estorvo que Ihe tiravam de sua direção natural. "Como não sou outra coisa senão literatura e nada posso ser ou quero de diverso, meu emprego nunca pode me monopolizar, embora bem possa me arruinar.", escreveria ele ao próprio Diário. Por isso, ele a tudo renuncia em favor da literatura - "Quando se tornou evidente a meu organismo que escrever é a direção mais fecunda de minha natureza, tudo para aí foi puxado e esvaziou todas as capacidades que se voltavam para as alegrias do sexo, do comer, do beber, da meditação filosófica, da música. Era necessário, porque, somadas, minhas forças eram tão poucas que só assim reunidas podiam servir regularmente à meta de escrever". ${ }^{7}$ Pelo dilaceramento, Kafka sente-se muito próximo da loucura. "Escrever me mantém vivo. Com isso naturalmente não penso que minha vida seja melhor quando não escrevo. Ao contrário, é muito pior e, insuportável, deve terminar na loucura". ${ }^{8}$

A dupla conexão que o afã literário mantém com a loucura - sua maneira de libertar-se de seu completo domínio - reaparece quando ele compara essa relação no plano das imagens religiosas. Sua paixão por escrever é referida como o único meio de que dispõe para salvar-se. A esta altura, faz-se necessário insistir no fato de que sua indecisão é um traço constante em busca de uma definição existencial. Se a idéia de abandonar a casa paterna e se responsabilizar pela própria família também lhe parecera uma maneira de concentrar sua força dispersa, por outro lado sua correspondência com Felice evidencia sua busca de convencê-la da inadequação de se casar com ele. Na tentativa de convencer a noiva, escreve ao pai de Felice pensando em uma interferência:

6 KAFKA, Franz. Cartas a Felice. Citado em: LIMA, Luiz Costa. Op. Cit. Pág. 25.

7 KAFKA, Franz. Diários 1910-1923. Citado em: LIMA, Luiz Costa. Op. Cit. Pág. 26.

8 KAFKA, Franz. Diários 1910-1923. Citado em: LIMA, Luiz Costa. Op. Cit. Pág. 27.

28

Qevista 丹ernáculo 
"A sua filha, cuja natureza de moça saudável a destinou a uma efetiva felicidade matrimonial, haverá de viver junto a tal tipo de homem? Terá de suportar uma vida monástica com um homem que, embora a ame como nunca amara alguém mais, por conta de sua decisão irrevogável, passa a maior parte do tempo em seu quarto ou a caminhar sozinho?"9

A contradição que Felice nele desperta é estímulo para a criação literária. O alcance desta é constatado em anotação de 14 de agosto de 1913. "Deduções de "O Julgamento" aplicadas ao meu caso. É a ela que indiretamente devo haver escrito o relato. Mas Georg [o protagonista] morreu por causa da noiva." ${ }^{10}$ Felice, ao mesmo tempo, é sedução e ameaça, estímulo para a criação e eminência da catástrofe.

A respeito da indecisão existencial de Kafka é preciso sinalar, também, que a figura do pai é peça indispensável. Em seu diário de 14 de dezembro de 1911, Kafka se refere a uma das muitas discussões em que seu pai Hermann o recrimina por não se empenhar com a fábrica. "Negavame a possibilidade de usar todo o tempo para a literatura"11, dizia. Talvez nenhuma anotação seja tão reveladora a respeito de como Kafka via a constituição da sua individualidade, que um fragmento de caráter autobiográfico, que reproduzimos aqui pela sua profunda relevância:

"Cada homem é singular e chamado a agir em virtude de sua singularidade. É preciso contudo que tome gosto por sua singularidade. A julgar por minha experiência, tanto na escola como em casa se trabalhava para que a singularidade desaparecesse. Dessa maneira se facilitava o trabalho da educação e também a vida da criança, que, entretanto, antes devia amargar a dor provocada pela coerção. Um garoto, por exemplo, que chega à noite lendo uma história excitante, nunca compreenderá por meio de uma argumentação restrita a seu caso que deva interromper o livro e ir dormir (...) Essa era minha singularidade. Ela era reprimida fechando-se o gás e deixando-me sem luz. (...) Eu sentia apenas a injustiça que me faziam; ia tristemente dormir e se desenvolvia o começo do ódio que de certo modo determinou minha vida na família e, desde então, toda minha vida. A proibição de ler é por certo apenas um exemplo característico pois agia profundamente. (...) Se já se condenava uma singularidade exposta às claras, teriam de ser muito mais graves aquelas que mantinha escondidas, nas quais eu mesmo já reconhecia algo de ilícito. (...) As singularidades que exibia aumentavam à medida que eu me aproximava da vida a meu alcance. Nenhuma salvação porém sucedeu; a quantidade de coisas mantidas em segredo não diminuiu por isso; a uma observação mais fina, descobria-se que nunca mais tudo poderia ser confessado". ${ }^{12}$

Não importa que, materialmente, o acidente tivesse tido o impacto que lhe empresta, mas que assim o interprete. Neste sentido, Kafka se

9 KAFKA, Franz. Cartas a Felice. Citado em: LIMA, Luiz Costa. Op. Cit. Pág. 32.

10 KAFKA, Franz. Diários 1910-1923. Citado em: LIMA, Luiz Costa. Op. Cit. Pág. 33.

11 KAFKA, Franz. Diários 1910-1923. Citado em: LIMA, Luiz Costa. Op. Cit. Pág. 30.

12 KAFKA, Franz. Diários 1910-1923. Citado em: LIMA, Luiz Costa. Op. Cit. Pág. 34. 
socializa a partir de uma proibição, de uma proibição precisa: a de continuar a ler além da hora permitida. Segundo Costa Lima, "a leitura interditada se converte, retrospectivamente, em germe do ódio com que encorará a seu meio". ${ }^{13}$ O fato é que, no caso, se estabelece um fosso entre a proibição à leitura e a instituição interditora. Essa divisória teria se enrijecido nos termos envolvidos, leitura e família, que obsedam sem descanso ou solução a pessoa de Kafka. Por isso, o pai tornara-se uma condensação do poder social. "Os juízes, comissários, burocratas, etc. não são substitutos do pai; é antes o pai que é um condensado de todas essas forças, às quais ele próprio se submete e convida seu filho a submeter-se". ${ }^{14}$ Benjamin se refere da seguinte maneira: "Há muitos indícios de que o mundo dos funcionários e o mundo dos pais são idênticos para Kafka. Essa semelhança não os honra."15

Portanto, teria a palavra, para Kafka, o mesmo valor da escrita que pretende limpar a alma dos seus mais íntimos segredos? - questiona Costa Lima. Diferentemente de Rousseau, para quem a palavra tinha a força de revelar, aquém de toda hipocrisia, de todo compromisso com as convenções e autoridade, Kafka age como que consciente da mudança que provoca, pois para ele nenhuma liberação é mais possível. Não se trata de confessar para atingir a absolvição - a culpa que o acompanha e que esconde à vista dos outros não se resgata porque este agora se converta em palavra manifesta. "Transformada em escrita, a leitura impedida na infância se metamorfoseia na literatura que não redime. Sua exigência absoluta expõe sua proximidade com a loucura". ${ }^{16}$ Proximidade que, como já vimos, é ambivalente: a literatura é tanto defesa contra a loucura como sua modalidade de acesso.

Se insistirmos na comparação entre Kafka e Rousseau, perceberemos como Kafka toma um rumo diferente daquele último. Enquanto Rousseau tinha a linguagem por instrumento de revelação e transparência, Kafka é consciente de que, entre o ponto de revelar e o momento da revelação, há uma distância indeterminada. A relação entre a individualidade e a escrita ganha um passo relevante: não há relação direta entre uma e outra; a escrita começa mesmo antes de ser escrita. A relação entre a mimesis e a linguagem seria explorada por Kafka na forma de uma encenação que convoca causas suplementares, derivadas da infância de fato vivida. ${ }^{17}$

"Não há uma observação do mundo interior como há uma do mundo externo.

13 LIMA, Luiz Costa. Op. Cit. Pág. 34

14 DELEUZE, G. \& GUATTARI, F. Kafka. Por uma literatura menor. Imago, RJ, 1977. Pág. 19.

15 BENJAMIN, Walter. Op. Cit. Pág. 157.

16 LIMA, Luiz Costa. Op. Cit. Pág. 36.

17 LIMA, Luiz Costa. Op. Cit. Pág. 37. 
Ao menos a psicologia descritiva é, provavelmente, no todo, um antropomorfismo, uma corrosão dos limites. O mundo interior apenas pode ser vivido, não descrito. A psicologia é a descrição do reflexo do mundo terrestre na superfície celeste $(\ldots)^{\prime \prime 18}$

Neste trecho, percebe-se como Kafka afirma que o seu mundo não é o da sua paisagem interna. Não se pode contar o que se vive descritivamente, porque não há expressão direta de como se vive. Seu contato será, pois, sempre interposto, ou seja, por uma maneira pela qual aquele que vive pode mostrar para si e para os outros como vive. Esta maneira é a marca da mimesis inevitável. Segundo Costa Lima, derivam daí duas conseqüências decisivas: o caráter não representacional de sua ficção, entendendo-se representação no sentido usual de expressão do eu autoral; e sua postura relativa à expectativa de encontrar, na literatura, a salvação.

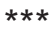

"A metamorfose"19 começa pelo despertar de Gregor Samsa, um caixeiro-viajante que acorda um dia transformado em um inseto. "Quando certa manhã Gregor Samsa acordou de sonhos intranqüilos, encontrou-se em sua cama metamorfoseado num inseto monstruoso". ${ }^{20} \mathrm{~A}$ primeira frase de "A Metamorfose" já nos lança em pleno universo kafkiano - uma consciência tragada por um corpo que lhe é estranho. Um corpo antinatural, a-histórico. O tom preciso e frio com que Gregor Samsa indaga a si mesmo "O que aconteceu comigo?" e a conclusão a que o narrador (ou Gregor?) chega "Não era um sonho." já é um indício de que o absurdo integra naturalmente o cotidiano.

Cabe aqui um parêntese para uma reflexão a respeito do narrador kafkiano. A este propósito, Costa Lima afirma que Kafka adota um discurso indireto livre, que consiste em manter o narrador no meio, entre o relato objetivo e a perspectiva pessoal da figura sobre que se relata. ${ }^{21}$ Neste caso, não se percebe que o procedimento em pauta afeta a expectativa do leitor quanto ao que a obra Ihe forneceria - uma informação sobre Gregor, cuja possível "metaforidade" não afetaria o que se julgava racional, por exemplo, afeito ao universo da razão iluminista. O narrador é convertido

18 KAFKA, Franz. Diários ¡910-1923. Citado em: LIMA, Luiz Costa. Op. Cit. Pág. 50.

19 "A Metamorfose foi publicada em um revista em 1915 e teve uma Segunda edição - em livro, em 1918, ou seja, é um dos trabalhos do autor que possuem uma versão definitiva, ao contrário de O Processo ou O Castelo, que, lançadas postumamente, não chegaram a Ter uma forma final estabelecida pelo autor. O texto foi escrito em 20 dias, em dezembro de 1912." Folha de São Paulo, caderno Mais!, 30 de maio de 1999. Por Adriano Schwartz, editor adjunto do Mais!.

20 KAFKA, Franz. A Metamorfose. Tradução de Modesto Carone. São Paulo; Companhia de Letras, 1997. Pág. 7.

21 LIMA, Luiz Costa. Op. Cit. Pág. 121.

Qevista Đernáculo 
em figura impassível -recolhe opiniões, registra reações do protagonista, mas nem sempre de dentro, nem tampouco ilumina com seu comentário, por exemplo, nunca fala sobre

Gregor Samsa. Esse atributo é denominado por Costa Lima como narrador inconfiável, pois "confiável era o narrador que supunha a existência de um pacto com o leitor, através do qual se assegurava os valores sociais circulação dentro da obra. A confiança no narrador era, por conseguinte, o efeito de uma confiança mais ampla: no limite, confiança na Lei que dirigia a sociedade." 22 O narrador kafkiano, enquanto inconfiável, torna a função do leitor e do intérprete muito mais complexa: o primeiro perde o seu "guia", o segundo já não se define como o que resgata uma intencionalidade. O narrador não apenas se "desinteressa" pelos personagens, mas deixa o leitor à deriva. Assim, a desconexão do narrador quanto ao destino dos personagens põe em xeque o hábito do leitor passivo, acostumado a se guiar pelos comentários do narrador, e a prenoção da interpretação como via de acesso à "verdade" do texto. Em outras palavras, diante do impasse moderno da perda da noção da totalidade, aquele que narra, em Kafka, não sabe nada ou quase nada sobre o que de fato acontece - do mesmo modo, portanto, o personagem.

Fora durante o sono que Gregor Samsa se converteu em um inseto inclassificável. ${ }^{23}$ "A não representatividade do inseto significa sua não compatibilidade com a homogeneização"24 - porque não é passível de caber em uma lei, acrescentaríamos. Não há pistas de uma explicação ao ocorrido, no entanto, a metamorfose está consumada. O ambiente - "um autêntico quarto humano", "Sobre a mesa (...) o mostruário de tecidos", a imagem "de uma dama de chapéu de pele e boá de pele"25 que ele havia recortado de uma revista ilustrada e colocado na parede, tudo estava como havia sido deixado na noite anterior.

Após uma breve análise de seu novo corpo, Gregor pensa em voltar a dormir e esquecer sua nova situação - mas já não há volta: "pois estava habituado a dormir do lado direito e no seu estado atual não conseguia se colocar nessa posição". ${ }^{26}$ Seus pensamentos passam, a partir de então, a estar voltados a sua profissão de caixeiro-viajante. Sua profissão

22 LIMA, Luiz Costa. Op. Cit. Pág. 123.

23 De acordo com Carone, essa abertura é praticamente intraduzível "no significado mais profundo da expressão 'ungeheueres Ungeziefer' (inseto monstruoso), uma vez que o adjetivo 'ungeheuer', que quer dizer, etimologicamente, aquilo que não é familiar, está diretamente relacionado com o substantivo 'Ungeziefer', que indica não apenas o inseto nocivo, mas também - do ponto de vista etimológico - o animal que, ao contrário dos que são domésticos, não se destina ao sacrifício pagão." Folha de São Paulo, caderno Mais!, 30 de maio de 1999. Pág 5. Texto de Modesto Carone.

24 LIMA, Luiz Costa. Op. Cit. Pág. 52.

25 KAFKA, Franz. A Metamorfose. Pág. 7.

26 KAFKA, Franz. A Metamorfose. Pág. 8.

32

Qevista §ernáculo 
Ihe desagradava, era-lhe imposta e "se não me contivesse, por causa dos meus pais, teria pedido demissão há muito tempo; teria me postado diante do chefe e dito o que penso do fundo do coração". ${ }^{27}$ Era preciso, porém, pagar a dívida dos pais.

Tal como Costa Lima havia proposto, observamos nesta passagem a ligação que Gregor Samsa realiza entre seu trabalho e seus pais, assunto este, aliás, extremamente recorrente nos demais escritos de Kafka. Logo veremos de que maneira pai e filho se relacionam, caracterizando a metáfora do "tribunal".

Enquanto Samsa não consegue se decidir se abandona a cama, os ponteiros do relógio seguem avançando. Ele está atrasado para pegar o trem que o levaria ao seu cliente. De fato, estava mais preocupado em como iria explicar ao chefe a sua ausência, pois certamente este enviaria alguém da firma para investigar o que teria ocorrido com o empregado. $O$ trabalho repugnava $\neg$ lhe, e apesar de sua excelência no serviço ("durante os cinco anos de serviço nunca havia ficado doente uma única vez") a profunda rigidez de seu chefe o incomodava - para ele, dizia Gregor mentalmente, "só existem pessoas inteiramente sadias, mas refratárias ao trabalho"28.

Entra em cena a família de Gregor, que haviam percebido que Gregor ainda permanecia em seu quarto, "contrariando as expectativas". ${ }^{29}$ Batem em sua porta e Ihe informam a hora. Depois, perguntam-Ihe se está doente, e, finalmente, pedem-Ihe que abra a porta. "Gregor entretanto não pensava absolutamente em abrir, louvando a precaução, adotada nas viagens de conservar as portas trancadas durante a noite, mesmo em casa." ${ }^{30}$ Instantes depois, conforme a expectativa de Gregor, chegava seu gerente. Apenas um atraso, um deslize e a honestidade de Samsa é já colocada em questão - "O chefe em verdade insinuou esta manhã uma possível explicação para suas omissões - ela dizia respeito aos pagamentos à vista que recentemente Ihe foram confiados." ${ }^{11}$ A porta separava-o de sua família e do trabalho, o seu quarto era sua intimidade. Intimidade esta que o seu próprio chefe se permitia invadir, revelando a pertinência a um meio social que desconhece o respeito à territorialidade estritamente pessoal. A insistência para que abrisse a porta reiterava a violência insinuada nas palavras, prescindindo o contato físico.

A indecisão surge feroz na mente de Gregor - abrir ou não a porta? Mesmo se optasse por abrir, conseguiria descer da cama? Seus 
movimentos, ainda pouco habituados à nova condição, estavam bastante limitados, e suas perninhas se movimentavam sem ritmo preciso. Decidiuse por arriscar -lançou-se num movimento e caiu da cama, de costas. O estrondo se fez ouvir desde a sala de estar, onde permaneciam sua família e seu gerente. Como a insistência para que abrisse a porta continuasse, tentou explicar sua situação através de um mal-estar momentâneo, mas para sua surpresa, ninguém havia compreendido o que dizia. A incompreensão do que Samsa havia dito causou estupor. "Será que ele está nos fazendo de bobo?", perguntava o gerente aos pais. "Você precisa ir imediatamente ao médico. Gregor está doente. Você ouviu Gregor falar, agora?" disse a mãe à irmã de Gregor. "Era uma voz de animal." disse novamente o gerente. ${ }^{32}$ A confiança e a certeza de que haviam sido tomadas as primeiras decisões acalmaram Gregor - "(...) sentia-se novamente incluído no círculo dos homens e passou novamente a esperar do médico desempenhos excepcionais e surpreendentes."33

A ausência da irmã que saiu em busca do médico pode significar as boas relações que Kafka mantinha com sua irmã, como seus Diários bem demonstram. A rudeza dos familiares e do gerente de Gregor estaria fundada na condenação que estão infligindo ao filho/empregado. O quarto transforma-se em tribunal. Não há dúvida de que seu caso pessoal o motivava para a cena, mas não significa, por outro lado, que isso bastasse para escrevê-la. O temor que o protagonista sente não pode ser explicado pelo personagem, e tampouco pelo narrador, mas é possível desconfiar que esse "medo" abre uma trilha na conquista da verdade, como vimos na breve apresentação dos argumentos de Costa Lima, apresentados anteriormente.

Samsa, realizando um esforço homérico para se movimentar, consegue abrir a porta antes da chegada de sua irmã. Ao sair, o gerente dá um grito e retrocede, a mãe desmaia e o pai se põe a chorar. O estupor foi geral. Gregor tenta acalmar o gerente e evitar a demissão, mas este se afastou e foi embora (não sem a insistência dos pais para que ficasse). 0 pai se enfurece e pôs-se a colocar Gregor de volta em seu quarto, com a ajuda de uma bengala e de um jornal. Como o próprio narrador afirma, "a fuga do gerente pareceu perturbar por completo o pai, que até então tinha permanecido completamente sereno". ${ }^{34}$ Gregor já não identificava seu pai naquela ação, e após insistir em se explicar com o pai, desiste e recua de volta para seu quarto, onde permaneceu novamente fechado.

Em princípio, Kafka concebeu "A Metamorfose" como um peque-

32 KAFKA, Franz. A Metamorfose. Pág. 22.

33 KAFKA, Franz. A Metamorfose. Pág. 23.

34 KAFKA, Franz. A Metamorfose. Pág. 29. 
no conto que terminava com a primeira parte da história. Mas, tendo terminado a primeira parte, sente um desejo ilimitado de verter-se de volta à história, como expressa em carta a Felice de 23 de novembro de 1912: "a pequena história silenciosamente começa a converter-se em uma história maior". Ao dia seguinte, Kafka realiza uma leitura da obra (primeira parte) aos amigos que supõem que esta estava completa, como afirmou Max Brod em suas impressões daquela ocasião.

A segunda parte da obra, apresenta o novo cotidiano da família após a nova situação de Gregor. A princípio, sua irmã decide-se por cuidar das necessidades básicas de Gregor - dava-lhe comida e limpava seu quarto. Vivendo estritamente dentro dos limites de seu quarto, Gregor agora se inteirava das conversas da família ouvindo-as pelas paredes. Descobrira, assim, que seu pai de fato tinha suas economias que durariam por algum tempo (já que era Gregor que sustentava a todos), e que haveria a necessidade dele [o pai] voltar a trabalhar. Tempos depois a nova situação deste último surpreenderia Gregor - "era aquele ainda o seu pai? O mesmo homem que costumava ficar enterrado na cama, exausto, quando Gregor partia para uma viagem de negócios? (...) Agora, porém, ele estava muito ereto, vestido com uniforme azul justo, de botões dourados..."35

A captação do conflito de Kafka com o pai representa também, muito mais do que a simples expressão do próprio drama vivido pelo escritor, o enfrentamento entre a geração jovem e a que resiste em se aposentar. Fingindo-se de débil, o pai de Gregor era desleal ao filho. Diante dele, o pai só considerava adequada a severidade, e isto se tornaria claro na situação em que Gregor, ao sair de seu quarto, é bombardeado por maçãs atiradas por seu pai. Uma delas literalmente penetrou nas costas dele.

Por este evento, podemos esclarecer efetivamente os valores que norteavam o Gregos-inseto e o próprio Kafka. A mãe e irmã de Gregor dispõem-se a retirar os móveis de seu quarto, para deixar-lho mais transitável -sabiam que sua única distração era ficar andando pelas paredes e pelo teto. No entanto, Gregor percebe que a intenção de esvaziar seu quarto deixa um problema - o que deveria salvar? "Realmente, não sabia o que salvar primeiro, então viu, saliente na parede de resto vazia, a imagem pendurada da dama toda vestida de peles, rastejou às pressas para $\mathrm{o}$ alto e comprimiu-se contra o vidro, que o reteve e fez bem à sua barriga quente." ${ }^{36}$ Era a imagem de Felice ali representada, sua força derradeira, como Kafka mesmo se referia, em uma carta de 11 de dezembro de 1913: "Não é fato necessário nenhum empurrão. Apenas a retirada da última for- 
ça aplicada sobre mim e chegarei a um desespero que me despedaçara." 37 A força advinda de Felice era esta força, que engendraria a força interna e levaria a tensão entre o matrimônio e a literatura.

A frágil estabilidade da família se rompe definitivamente na terceira parte da obra, quando Gregor é negligenciado pela própria mãe e, em seguida, pela irmã. De fato, conta-nos o narrador, Gregor era um fardo que vinha aumentando cada vez mais. Devido às dificuldades econômicas, a intenção de vender o apartamento não podia ser efetivada, pois não se sabia como Gregor seria removido. A situação chega ao limite quando ele irrompe na sala de estar enquanto três inquilinos, que alugavam quartos no apartamento, ouviam sua irmã tocar violino. Frente ao escândalo causado, a família decide - é preciso se livrar de Gregor. O julgamento é unânime e a sentença está dada. O próprio réu também está decidido a evadir-se. Ao passar a noite, amanhece morto e seu fim não é declarado - a empregada encontra uma maneira de jogá-lo fora, e já está tudo em ordem.

A decisão voluntária de Gregor em se evadir, a fim de não criar mais algum pesadelo a sua família, pode ter se tornado legítima em sua morte. A morte voluntária seria, de fato, um indício bastante grande de que a metamorfose também o seria. Afinal, a imagem da dama toda vestida de peles tinha sido recortada por ele "fazia muito pouco tempo de uma revista ilustrada e colocado numa bela moldura dourada", dizia o narrador, naquele dia em que Gregor acordou de sonhos intranqüilos.

\section{Bibliografia}

BENJAMIN, Walter. Obras escolhidas. São Paulo: Editora Brasiliense, 1986.

COMPAGNON, Antoine. O demônio da teoria. Literatura e senso comum. Belo Horizonte, UFMG, 1999.

DELEUZE, G. \& GUATTARI, F. Kafka. Por uma literatura menor. Imago, RJ, 1977.

Folha de São Paulo, caderno Mais!, 30 de maio de 1999.

LIMA, Luiz Costa. Limites da voz: Kafka. Rio de Janeiro; Rocco, 1993.

KAFKA, Franz. A Metamorfose. Tradução de Modesto Carone. São Paulo; Companhia de Letras, 1997. 